\title{
Negative affect, affect-related impulsivity, and receptive syringe sharing among people who inject drugs
}

\author{
Mary Ellen Mackesy-Amiti, \\ Community Outreach Intervention Projects, School of Public Health, University of Illinois at \\ Chicago \\ Basmattee Boodram, \\ Community Outreach Intervention Projects, School of Public Health, University of Illinois at \\ Chicago \\ Geri Donenberg \\ Community Outreach Intervention Projects, School of Public Health, University of Illinois at \\ Chicago
}

\section{Abstract}

Receptive syringe sharing (RSS) among people who inject drugs (PWID) is a risk factor for hepatitis $\mathrm{C}$ virus and HIV infections. PWID with borderline personality disorder (BPD) have increased risk of RSS, but it remains unclear what drives this association. This study used ecological momentary assessment (EMA) to study characteristics associated with BPD, and RSS among PWID. We recruited PWID, age 18-35, through two Community Outreach Intervention Projects syringe service program sites in Chicago, Illinois, USA. After a baseline interview, participants used a mobile phone app to respond to momentary surveys on mood, substance use, and injection risk behavior for two weeks. For each momentary assessment, ratings on negative mood descriptors were combined to create measures of total negative affect (NA), and NA components of dejection, shame, anger, irritability, and worry. RSS was defined by participant responses indicating that they had used a syringe that someone else had used. We estimated mixed effects logistic models, regressing RSS on baseline affect-related impulsivity, lagged momentary $\mathrm{NA}$, and the interaction term. Out of 163 participants who completed at least two EMA assessments, 152 (93\%) reported at least one injection event and had valid pre-injection mood assessments required to be included in the analysis. We found that affect-related impulsivity, combined with worried mood in the hours preceding the injection episode, predicted increased risk of RSS. PWID having difficulties with emotion regulation may be at increased risk of RSS during periods of anxiety or tension.

Correspondence concerning this article should be addressed to Mary E. Mackesy-Amiti, University of Illinois at Chicago, School of Public Health / COIP, 1603 W. Taylor St. Chicago, Illinois 60612 USA. mmamiti@uic.edu.

Basmattee Boodram is now with the Division of Community Health Sciences, School of Public Health, University of Illinois at Chicago; Geri Donenberg is now at Center for Dissemination and Implementation Science, College of Medicine, University of Illinois at Chicago.

A preprint of this paper has been made available on PsyArXiv, doi: 10.31234/osf.io/4ewn6

Submitted to Psychology of Addictive Behaviors on March 27, 2020 


\section{Keywords}

ecological momentary assessment; emotion dysregulation; hepatitis $\mathrm{C}$; injection drug use; borderline personality disorder

The prevalence and incidence of hepatitis $\mathrm{C}$ virus (HCV) infections in the United States has been on the rise for several years, with 41,200 new HCV infections occurring in 2016 alone (Centers for Disease Control and Prevention, 2018). New HCV infections increased most rapidly among young people (20 to 29 years old) (Centers for Disease Control and Prevention, 2017), fueled by an increase in injection drug use (IDU) (Chatterjee et al., 2011; Zibbell et al., 2018; Zibbell et al., 2015). An estimated $40 \%$ of people in the U.S. with recent IDU are HCV infected (Grebely et al., 2018). Sharing syringes and other injection equipment among people who inject drugs (PWID) is a significant risk factor for transmission and acquisition of blood-borne diseases including HIV and HCV (Centers for Disease Control and Prevention, 2012; Hagan et al., 2001; Pouget, Hagan, \& Des Jarlais, 2012; Thorpe et al., 2002). Recent research has underscored heightened behavioral risk among PWID with co-occurring mental health disorders, placing them at increased risk of HIV and HCV infection (Disney et al., 2006; Gilchrist, Blazquez, \& Torrens, 2011; King, Kidorf, Stoller, \& Brooner, 2000; Majer, Komer, \& Jason, 2015; Roy, Levesque, Bruneau, Jutras-Aswad, \& Bertrand, 2014).

Models commonly used to explain individual variation in risky behavior have included factors such as knowledge, beliefs, attitudes, and behavioral skills as predictors (Bandura, 1994; Fishbein \& Middlestadt, 1989; Fisher, Fisher, \& Harman, 2003). Environmental and contextual factors are also important (Boodram, Golub, \& Ouellet, 2010; Boodram, Hotton, Shekhtman, Gutfraind, \& Dahari, 2018; Boodram, Mackesy-Amiti, \& Latkin, 2015; German, Davey, \& Latkin, 2007; Hotton \& Boodram, 2017; Roy et al., 2011), especially in relation to planning public health responses, including harm reduction, increased testing, linkage to care, and availability of curative direct-acting antiviral (DAA) HCV therapy (Boodram et al., 2020; National Academies of Sciences Engineering and Medicine, 2016; Platt et al., 2018). The role of affect and emotion regulation in determining injection risk behavior, on the other hand, has received little attention. These are particularly important given the high rates of affective disorders among people who use drugs (Compton, Thomas, Stinson, \& Grant, 2007; Grella, Karno, Warda, Niv, \& Moore, 2009; Myrick \& Brady, 2003) and the potential to identify novel targets for risk-reduction interventions. While negative affect and poor emotion regulation are implicated in the development and maintenance of substance use disorders (Baker, Piper, McCarthy, Majeskie, \& Fiore, 2004; Cheetham, Allen, Yucel, \& Lubman, 2010; Kassel et al., 2007; G. Koob \& Kreek, 2007; G. F. Koob, 2009), as well as other types of risky behavior (Weiss, Sullivan, \& Tull, 2015), few studies have examined the relationship between negative affect and injection risk behavior (Mackesy-Amiti, Donenberg, \& Ouellet, 2014; Pilowsky, Wu, Burchett, Blazer, \& Ling, 2011; Stein, Solomon, Herman, Anderson, \& Miller, 2003).

Recent studies in Australia (Darke, Williamson, Ross, Teesson, \& Lynskey, 2004) and the United States (Mackesy-Amiti et al., 2014) have found an association between borderline 
personality disorder (BPD) and risky injection practices. BPD is common among illicit drug users including PWID (Chen et al., 2011; Mackesy-Amiti, Donenberg, \& Ouellet, 2012; Mills, Teesson, Darke, Ross, \& Lynskey, 2004; Rounsaville et al., 1998; Torrens, Gilchrist, \& Domingo-Salvany, 2011; Trull, Sher, Minks-Brown, Durbin, \& Burr, 2000; Verheul, 2001). Individuals with BPD experience rapid mood swings, heightened emotional reactivity, vulnerability to negative affect, and slow recovery from dysphoric states (Crowell, Beauchaine, \& Linehan, 2009; Lieb, Zanarini, Schmahl, Linehan, \& Bohus, 2004; Linehan, 1993). This leads to dysfunctional response patterns during emotionally challenging events.

Impulsivity is also a hallmark symptom of BPD. Recently, researchers have differentiated multiple types of impulsivity (Whiteside \& Lynam, 2001). Sensation seeking (a tendency to seek excitement and adventure) is differentiated from negative urgency (a tendency to commit rash or regrettable actions as a result of intense negative affect) and (lack of) premeditation (the tendency to delay action in favor of careful thinking and planning). BPD is particularly associated with negative urgency, the tendency to act impulsively when experiencing negative affect (Cyders \& Smith, 2007; Peters, Upton, \& Baer, 2012; Tragesser $\&$ Robinson, 2009). Negative urgency has been found to predict risky sexual behavior (Deckman \& DeWall, 2011) as well as self-harm behavior (Dir, Karyadi, \& Cyders, 2013; Riley, Combs, Jordan, \& Smith, 2015) and may be an important construct linking BPD with risky injection behavior. Innovative methods are needed to clarify the dynamic relationship between mood states and injection behavior.

Ecological momentary assessment (EMA) is an optimal method for studying dynamic processes, such as mood and behavior, and to minimize problems of retrospective recall bias (Ebner-Priemer \& Trull, 2009a, 2009b; Shiffman, Stone, \& Hufford, 2008). Biases in retrospective reporting of events and experiences have been demonstrated in a number of empirical studies and may be exacerbated by mental health problems. For example, individuals with BPD may underestimate positive emotions and overestimate negative emotions in retrospective accounts, while healthy control participants exhibit the opposite pattern (Ebner-Priemer et al., 2006). EMA allows the study of within-person variability that is not possible with cross-sectional observational studies that provide information about between-person differences only. Moreover, EMA allows the study of the interplay of mood and behavior over time in a real-life context.

In this study, we sought to develop an understanding of the mechanisms that link BPD or emotion dysregulation with risky injection behavior. We conducted EMA with PWID using a mobile phone app to assess mood and injection risk behavior over a period of two weeks (Mackesy-Amiti \& Boodram, 2018). Participants completed a screening for BPD and measures of emotion dysregulation and impulsivity at baseline. In a separate paper (Mackesy-Amiti \& Donenberg, 2020) we report our findings on emotion dysregulation and patterns of negative affect in this sample, confirming that symptoms of BPD and emotion dysregulation were associated with more intense and unstable NA. In this paper, we examine the associations between EMA-reported receptive syringe sharing, momentary negative affect preceding the injection event, and baseline measures of affect-related impulsivity. We hypothesized that respondents with a high score on measures of affect-related impulsivity 
would be more likely to engage in risk behavior such as receptive syringe sharing when experiencing high levels of negative affect.

\section{Methods}

\section{Participant recruitment}

The research was conducted at two field sites operated by Community Outreach Intervention Projects (COIP) in Chicago, Illinois, U.S. from February 2016 to June 2017. These locations provide harm reduction services including a syringe services program (SSP), HIV and HCV testing, counseling and case management services, and prevention-focused street outreach. People between the ages of 18 and 35 who injected illicit drugs in the past 30 days were eligible for the study. Participants were excluded if they could not read and understand English. COIP's SSP clients were invited to participate and were encouraged to refer other PWID to the study. Current injection was verified by trained counselors who inspected for injection stigmata and, when stigmata were absent or questionable, evaluated knowledge of the injection process. Age was verified with a driver's license or a state identification card. Individuals who met the eligibility criteria were offered $\$ 10$ to complete a screening questionnaire assessing symptoms of borderline personality disorder (MacLean Screening Instrument for BPD) (Zanarini et al., 2003). This screening was initially planned to ensure that at least $50 \%$ of our sample met the screening criteria for BPD (score 27 ). We expected $30-40 \%$ of subjects would score above the cutoff. It soon became clear that there would be no need to selectively sample on BPD screening, however we retained the 2-step procedure.

\section{Procedures}

Clients were recruited after they completed their visit at a COIP SSP. After the interviewer administered the written informed consent procedure, participants completed the screening questionnaire, followed by a baseline audio computer-assisted self-interview (ACASI) and were compensated $\$ 25$. Participants were then trained on the use of the mobile phone app to access the survey and answer the questions. An Android mobile phone (4.4 KitKat OS, retail value \$50) was provided, or participants could choose to use their own device. Phones were encrypted, password protected, and the EMA app and study-related messages were protected with an app lock. A mobile contact number was provided for participants to ask questions or report technical problems. Study personnel responded promptly to assistance requests during usual operating hours and as soon as possible outside of usual hours to troubleshoot and resolve issues. Participants received mobile surveys for 15 days (including partial first day); they were paid for each survey completed and could earn up to $\$ 9$ per day. At the end of the observation period, participants were notified to return to the field site for a brief follow-up survey, and to collect their compensation. The study coordinator attempted to locate participants who failed to appear for the final interview to document the reason for nonreturn. Study procedures were approved by the University of Illinois at Chicago Institutional Review Board.

We used the ilumivu mEMA platform (version 5.8; ilumivu Inc., 2016), that includes a web site for creating and managing surveys and data, and a mobile phone app to deliver the assessments. The mEMA app allows responses to be entered on the cell phone even when 
there is no active internet connection, although an internet connection is needed to upload data. Assessments were scheduled to occur 4, 5, or 6 times per day at random time-points within a 12-hour window. As reported in a previous paper (Mackesy-Amiti \& Boodram, 2018), we varied the number of daily assessments across participants to examine the impact on participation and completion. Start and end time were decided by the participant at the beginning of the study to accommodate individual schedules (nearly all within 08:00 to 23:00). Each day for 2 weeks, participants received a notification when an assessment was requested, followed by reminders after 5 minutes and 10 minutes if the survey was not accessed. After 20 minutes the survey became unavailable until the next scheduled assessment.

All participants could potentially earn up to $\$ 9.00$ per day regardless of the assigned number of assessments. Participants earned a bonus of $\$ 10$ for completing at least $80 \%$ of the assessments, and an additional $\$ 10$ if they completed $90 \%$ of the assessments. Participants who used their own mobile phone received $\$ 25$ to offset data usage. Participants who used a project phone received a minimum payout of $\$ 25$ for returning the phone. Participants received daily text message updates on their progress showing the number of assessments completed, and the number needed to reach the bonus level. If a participant missed all assessments on any day, they received a reminder to contact study personnel for assistance. If a participant did not complete any assessments for two consecutive days, the site study coordinator attempted to contact them to offer assistance. If a participant did not complete any assessments for a third day, they were notified to return to the study site. Detailed information on participation rates is reported in our previous paper (Mackesy-Amiti \& Boodram, 2018).

\section{Measures}

Baseline Assessment.-The following measures were included in the baseline ACASI (average time to complete 45 minutes).

Borderline Personality Disorder.: The McLean Screening Instrument for Borderline Personality Disorder (Zanarini et al., 2003) consists of ten yes-no items. The score is computed as the total number of items positively endorsed. Using a cutoff score of 7 or more items endorsed, the screening instrument achieved good sensitivity (.81) and specificity (.85) for the diagnosis of DSM-IV BPD, and criterion and construct validity have been supported (Gardner \& Qualter, 2009; Patel, Sharp, \& Fonagy, 2011). Minor changes were made to adapt the instrument for computer-assisted selfadministration. Internal consistency in the current sample was acceptable $($ alpha $=0.77)$.

Sociodemographic and Geographic Characteristics.: The questionnaire assessed demographic characteristics including sex, sexual orientation, race or ethnicity, and highest level of education attained. Residential zip code, sources of income, places lived or slept, homelessness, and drug treatment were assessed with reference to the past six months. Current participation in drug treatment was also assessed. Homelessness was measured with two different questions: 1) "In the past 6 months, have you thought of yourself as homeless?" and 2) "In the past 6 months, have you slept in a shelter, car, abandoned 
building, public park, squatting place, or other non-dwelling for more than 7 nights in a row?" Based on these two questions, we created a composite variable with three levels: 1) not homeless, 2) thought of as homeless, 3) slept in non-dwelling.

Risk Behavior and HIV/HCV Status.: The NIDA Risk Behavior Assessment (National Institute on Drug Abuse, 1993), a widely used instrument with established reliability and validity (Needle et al., 1995; Weatherby et al., 1994), was administered to assess substance use and sexual risk behavior, and HIV testing history and outcomes. Items were added to measure $\mathrm{HCV}$ testing history and outcomes. Injection behaviors were assessed with reference to the past 6 months. Receptive syringe sharing ("Thinking about all the times you injected in the past 6 months, how often did you inject with needles that had been used before you by somebody else, even if the needle was cleaned first?") was measured on a 7point Likert type scale from "never" to "always". We recoded responses into 3 categories: never, rarely, and sometimes (less than half the time to always).

Emotion Dysregulation.: The Difficulties in Emotion Regulation Scales (DERS) (Gratz \& Roemer, 2004) is a self-report instrument with six sub-scales, including non-acceptance of emotional responses, difficulties engaging in goal directed behavior, affect-related impulsivity, lack of emotional awareness, limited access to emotion regulation strategies, and lack of emotional clarity. The impulsivity subscale includes items such as "When I'm upset, I have difficulty controlling my behaviors," and "When I'm upset, I feel out of control." Scores are coded such that high scores indicate greater emotion dysregulation. The DERS has demonstrated adequate construct and predictive validity (Gratz \& Roemer, 2004), and has been validated in samples of cocaine (Fox, Axelrod, Paliwal, Sleeper, \& Sinha, 2007) and alcohol (Fox, Hong, \& Sinha, 2008) dependent respondents. Total and subscale scores are computed as the sum of item ratings. In the current sample, internal consistency was excellent for the total scale ( $\mathrm{alpha}=0.95)$ and good for all subscales (alpha $=0.82$ 0.87). The mean DERS impulsivity score was 16.64 (SD 5.54; IQR 12, 20).

Impulsivity.: The SUPPS-P Impulsive Behavior Scale (Cyders, Littlefield, Coffey, \& Karyadi, 2014) is a short version of the Urgency, Premeditation, Perseverance, Sensation Seeking, Positive Urgency Impulsive Behavior Scale (UPPS-P) (Cyders et al., 2007; Whiteside \& Lynam, 2001; Whiteside, Lynam, Miller, \& Reynolds, 2005), consisting of 20 four-point Likert scale items measuring five dimensions of impulsivity. The abbreviated scale demonstrated criterion validity similar to the full scale (Cyders et al., 2014). Subscale scores were computed as the mean of item ratings. The negative urgency (NU) scale includes items such as "When I feel bad, I will often do things I later regret in order to make myself feel better now," and "When I am upset I often act without thinking." In the current sample, internal consistency was acceptable for NU (alpha $=0.70)$. The mean NU score was 3.21 (SD 0.58; IQR 2.75, 3.75).

EMA Measures.-The EMA assessments included questions on current mood, context (where and who with), current intoxication or withdrawal, injection since last report, and if applicable, recency of injection, and syringe and equipment sharing at last injection. 
Momentary affect.: Participants were presented with a list of 20 mood descriptors and instructed to select up to four that described their current mood. Options also included not sure and none of these. For each selected item, participants then rated their mood intensity on a 10-point slider scale. The item set was developed largely based on the Positive and Negative Affect Schedule - Expanded Form (PANAS-X) (Watson \& Clark, 1999; Watson, Clark, \& Tellegen, 1988) through three rounds of pretesting with PWID recruited at COIP field stations. The items retained included two "serenity" items (calm, relaxed), six positive affect (PA) items (happy, energetic, excited, confident, determined, inspired) and ten PANAS negative affect (NA) items (angry, angry at self, ashamed, disgusted, distressed, downhearted, irritable, sad, scared, upset). We also included two new NA items relevant to this population (frustrated and worried), resulting in a 12-item NA scale. In pretesting, internal reliability was high for both the 6-item PA scale (alpha=0.81) and the 12-item NA scale (alpha=0.91), and the pick-4 format did not affect NA or PA intensity.

Unselected items were scored zero, and the mood ratings were averaged for all 12 negative mood descriptors to create a measure of general NA at each assessment. Similarly, the six positive mood ratings were averaged to create a measure of general PA. When a participant selected none or not sure and no mood items were rated, affect intensity was scored as zero.

To identify within-subject (state) components of NA, we conducted a multilevel exploratory factor analysis of the twelve NA ratings in Mplus (version 8; Muthén \& Muthén, 2017), with the between-subject level unrestricted. Factors were subjected to GEOMIN rotation, and model fit was assessed by comparative fit index (CFI), root mean squared error of approximation (RMSEA), and standardized root mean square residuals (SRMR). We created measures of NA components by computing the mean of the two highest loading items for each factor (see Appendix A). Five within-subject level factors were extracted (CFI=0.99, RMSEA $<0.001$, SRMR=0.008). The NA components are 1) shame: ashamed and angry at self, 2) dejection: downhearted and distressed, 3) irritability: frustrated and irritable, 4) anger: angry and upset, and 5) worry. worried and scared.

Current state of intoxication or withdrawal.: Participants were asked, "Are you currently under the influence of alcohol or any drug (buzzed, high)?" and if they answered affirmatively they were asked to report the substance(s) involved (alcohol, marijuana, cocaine, heroin, opiate med, other). They were also asked, "Are you currently feeling any hangover or withdrawal effect?" and if so, to report which substance(s) were involved.

Injection drug use and syringe and equipment sharing.: Participants were asked, "Did you inject any drug since your last report?" If they answered affirmatively, they were asked "When did you last inject?" with response options ranging from 1 (less than 1 hour ago) to 7 (more than 12 hours ago). If injection was reported, participants were asked the following questions. (i) When you injected the last time did you: a) use a brand new syringe, b) re-use a syringe only you used before, or c) use a syringe that someone else had used? (ii) When you injected the last time did you: a) use new clean cooker, cotton $\&$ water, b) re-use any supplies that only you used before, or c) use any supplies that someone else had used? (iii) After you injected the last time did you give your syringe to someone else to use? Receptive 
syringe sharing (RSS) was indicated by responses that the participant had used a syringe that someone else had used.

\section{Analysis}

Regression analyses were conducted in Stata (version 15; StataCorp, 2017). We tested between-subject effects of trait NA, DERS impulsivity, and negative urgency (NU) on momentary NA using GEE regression. For the main analysis, we conducted mixed effects logistic regression analyses predicting RSS during reported injection events, with random intercepts for subject. Mixed models were estimated using 15 points of integration for increased accuracy. Day and time of day effects were included in all models, as well as homelessness, as these variables were associated with the EMA response rate. We tested between-subject variables including sex, race or ethnicity, BPD screen, DERS total score, DERS impulsivity, and NU. To test our hypothesis that PWID experiencing high affectrelated impulsivity would be more likely to engage in risk behavior during periods of elevated negative affect, we regressed RSS on lagged momentary NA (i.e. NA at the preceding EMA prompt), and interactions with DERS impulsivity and NU. Momentary affect ratings were subject-centered, and subject mean NA, computed over all reports during the 2-week observation period, was also included in the model to separate within and between-person effects (Curran \& Bauer, 2011). Lagged effects were computed based on completed EMA reports, ignoring missed EMA prompts. Sensitivity analyses were conducted to test the effect of varying length of time lag between affect rating and injection reports, by adjusting for length of time lag or excluding observations with time lags greater than 4 hours. In addition, we conducted separate exploratory analyses of each NA component, following the same analytical procedure. We also tested models including withdrawal symptoms as a within-subject factor, to rule out the possibility that withdrawal could explain the effects of NA. A final model of NA component effects included all significant interaction terms.

\section{Results}

All eligible subjects agreed to participate and were enrolled in the study. Out of 185 participants with baseline data, our sample was restricted to the $165(89 \%)$ who completed at least two mobile assessments during the two-week observation period, with an additional two subjects excluded due to missing data on the baseline instrument (total $n=163$ ). A previous paper reported on correlates of EMA response rate and study completion (Mackesy-Amiti \& Boodram, 2018). On average, participants responded to $43 \%$ of survey prompts, providing a total of 5,525 EMA responses, $99 \%(n=5,475)$ with non-missing data on injection. Homelessness was associated with study dropout and lower response rate, as well as syringe sharing. Characteristics of the available sample are shown in Table 1. Seventy percent of subjects scored at or above the cutoff $(\geq 7)$ on the BPD screener. Within this sample, $45 \%$ of EMA reports $(2,473 / 5,475)$ included an injection event; 59 of these events (2.4\%), reported by 21 individuals (13\%), included RSS. 


\section{Between subject factors}

The probability of RSS did not vary by subject sex, race or ethnicity, or age. Participants who reported being homeless at baseline (slept in a non-dwelling) were more likely to report RSS compared to others ( $\mathrm{OR}=5.79,95 \% \mathrm{CI} 1.21-27.61)$. Overall, momentary RSS was not associated with BPD screening status, DERS total score, DERS impulsivity, or negative urgency impulsivity.

\section{Momentary negative affect}

Overall momentary NA was significantly associated with trait negative affect $(b=0.09,95 \%$ CI 0.02-0.17) and DERS impulsivity ( $b=0.14,95 \%$ CI 0.06-0.21), but not with NU . Analyses of NA effects used lagged values; this necessarily restricted the analysis to observations with non-missing lagged affect ratings within the same day. Out of 2,471 observations that included an injection event and non-missing data on RSS, 63\% had a valid lagged affect rating recorded ( $\mathrm{N}=152$ subjects, 1,559 observations). Out of 912 injection events without a same-day lagged affect rating, about half (49\%) were due to being the first scheduled observation of the day. Eleven individuals who were low frequency responders did not contribute any observations to the analysis. The mean time lag was 3 hours (SD 1.58), ranging from 0.19 to 10.96 (IQR $[1.9,3.6]$ ), with $95 \%$ under 6 hours. RSS was reported on 40 (2.6\%) of these observations, by 15 individuals. Overall, momentary RSS was not associated with lagged total NA, dejection, shame, irritability, anger, or worry. Interactions between total NA and NA components and affect-related impulsivity are summarized in Table 2 (NU) and Table 3 (DERS impulsivity). DERS impulsivity interacted with total NA to predict greater likelihood of RSS. In addition, high affect-related impulsivity on both measures was associated with increased likelihood of RSS when respondents reported feeling worried or scared in the preceding time period. An interaction between NU and anger was observed in the opposite direction than predicted, such that NU was associated with increased likelihood of RSS when anger was relatively low (but not when anger was high), and anger was negatively associated with RSS when NU was high. Adjusting for the effects of withdrawal in the preceding time period had no substantial impact on the estimates. Analyses with time lags restricted to four hours or less, or including length of time lag as a covariate, also produced similar results. In the final model, shown in Table 4, we included the three interaction terms and computed the predicted probabilities of RSS. We plotted the estimated effects on contour heatmaps, using Shepard interpolation (Press, Teukolsky, Vetterling, \& Flannery, 2007) (Figure 1). Note that the distribution of NU is negatively skewed with a mean of 3.2, and 50\% of scores between 2.75 and 3.75. Darker color indicates a higher predicted probability of RSS. Panel (a) shows the effect of NU combined with worry, panel (b) shows the effect of DERS impulsivity with worry, and panel (c) shows the effect of NU with anger. The hotspots in the upper right corner of panel (a) and panel (b) show the effect of worry and high NU or DERS impulsivity.

\section{Discussion}

Previous research has found that PWID with BPD are more likely to engage in RSS (Darke et al., 2007; Darke, Ross, Williamson, \& Teesson, 2005; Mackesy-Amiti et al., 2014), a practice that places them at risk for HIV and HCV infections. Our study used ecological 
momentary assessment to study associations between negative affect, emotion dysregulation, affect-related impulsivity, and RSS among PWID. Specifically, we tested the hypothesis that those with high negative urgency or DERS impulsivity would be more likely to engage in RSS during periods of elevated negative affect. Our findings support that PWID who score high on DERS impulsivity are at relatively greater risk of RSS following elevated NA In addition, both DERS impulsivity and NU were associated with greater risk of RSS following a report of being worried or scared, feelings that indicate a state of tension, anxiety, or fear. In a test of construct validity, the PANAS Fear dimension (scared, nervous, jittery, etc.) was strongly associated with the Profile of Mood States (POMS) Tension-Anxiety dimension (tense, nervous, anxious, etc.) Worry or anxiety (for example, associated with avoiding withdrawal or fear of getting caught engaging in illegal behaviors) may lead PWID who are lacking emotion regulation skills to take risks that they might otherwise avoid. The interaction between NU and anger was in the opposite direction than predicted, and was not replicated for DERS impulsivity. This suggests it may be spurious, perhaps due to the small number of people with low $(<2) \mathrm{NU}$ scores.

Measures of DERS impulsivity and NU assess related yet distinct facets of affect-related impulsivity. DERS impulsivity items assess loss of control when experiencing emotional distress, while NU items capture rash and regrettable behavior. Negative urgency impulsivity is described as a maladaptive strategy for coping with unpleasant affect, taking impulsive action to achieve immediate relief regardless of the consequences (Cyders \& Smith, 2007, 2008). This disposition to engage in rash action contributes to risky behavior, including substance misuse and IDU (Mirhashem et al., 2017; Wardell, Strang, \& Hendershot, 2016). Negative urgency is also associated with self-harm behavior (Dir et al., 2013; Glenn \& Klonsky, 2010; Peterson, Davis-Becker, \& Fischer, 2014) and suicidal ideation (Anestis \& Joiner, 2011; Klonsky \& May, 2010; Lynam, Miller, Miller, Bornovalova, \& Lejuez, 2011), problems that are common among PWID and people with BPD. People with affect-related impulsivity may benefit from interventions that teach emotion regulation and distress tolerance skills. For PWID, such an intervention could be integrated with other harm reduction efforts to prevent risky behavior including syringe sharing and drug mixing, as well as augment treatment success.

\section{Limitations}

Participants in this study completed less than half of scheduled EMA assessments, potentially compromising the quality of the data collected. We reported on correlates of response rate in a previous paper (Mackesy-Amiti \& Boodram, 2018). Homelessness was an important factor associated both with response and study completion rates and with RSS. Non-response and study dropout by homeless participants may have contributed to low rates of reported RSS. In addition, many of the participants were regular clients of the SSP, and may engage is less risky behavior than PWID in general. The low rate of RSS reported during the study may have limited our ability to detect effects. A longer duration of observation may be needed to observe somewhat rare occasions of syringe sharing that nevertheless pose a serious risk to health. 
Our measure of momentary affect was comprised of a subset of items from one widely used measure of dimensions of affect. The pick-4 measure significantly reduces the burden on the participant, and still provides an adequate assessment of the respondent's mood on multiple dimensions (Mackesy-Amiti \& Donenberg, 2020). We included worried as a novel mood term as it was more frequently endorsed in pretesting than terms such as nervous or jittery. Future research on risk behavior among PWID should pay greater attention to this dimension of affect.

\section{Conclusions}

Difficulties with emotion regulation are common among PWID. One manifestation of emotion dysregulation is negative urgency impulsivity - a tendency to commit rash or regrettable actions as a result of intense negative affect. Our findings suggest that PWID with high negative urgency may be more likely to engage in risky injection behavior at typical levels of negative affect, and more so during periods of anxiety or stress.

Interventions that teach emotion regulation and distress tolerance skills may be beneficial for PWID and can be integrated into typical substance use and mental health programs.

\section{Acknowledgments}

This work was supported by the National Institute on Drug Abuse of the National Institutes of Health grant number R21DA039010. The content of this paper is solely the responsibility of the authors and does not necessarily represent the official views of the National Institutes of Health. We thank study participants for the time and effort they contributed to this study, and acknowledge the dedication of our staff members who conducted the interviews and otherwise operated field sites in a manner welcoming to potential participants.

\section{APPENDIX A}

Table A1.

Multilevel exploratory factor analysis of momentary mood intensity ratings: Within-subject factors

GEOMIN ROTATED LOADINGS

\begin{tabular}{|c|c|c|c|c|c|}
\hline Item & 1 & 2 & 3 & 4 & 5 \\
\hline Angry & 0.11 & $-0.08^{*}$ & 0.02 & $0.38^{* *}$ & -0.02 \\
\hline Angry at self & $0.61^{* *}$ & 0.00 & $0.04^{*}$ & 0.00 & 0.02 \\
\hline Ashamed & $0.43^{* *}$ & 0.00 & -0.08 & 0.01 & -0.01 \\
\hline Disgusted & $0.11^{*}$ & 0.06 & 0.01 & $0.21^{* *}$ & $-0.12^{* *}$ \\
\hline Distressed & 0.03 & $0.20^{* *}$ & $0.10^{* *}$ & 0.01 & 0.00 \\
\hline Downhearted & 0.00 & $0.63^{* *}$ & 0.00 & -0.01 & 0.00 \\
\hline Frustrated & 0.03 & 0.02 & $0.54^{* *}$ & 0.01 & 0.00 \\
\hline Irritable & -0.05 & -0.02 & $0.32^{* *}$ & 0.09 & 0.04 \\
\hline Sad & 0.01 & $0.11^{*}$ & $-0.14^{* *}$ & 0.11 & $0.19^{* *}$ \\
\hline Scared & 0.02 & -0.01 & -0.08 & 0.01 & $0.35^{* *}$ \\
\hline Upset & -0.04 & 0.02 & 0.03 & $0.32^{* *}$ & $0.33^{* *}$ \\
\hline Worried & 0.04 & -0.03 & 0.04 & -0.09 & $0.44^{* *}$ \\
\hline
\end{tabular}




\section{References}

Anestis MD, \& Joiner TE (2011). Examining the role of emotion in suicidality: Negative urgency as an amplifier of the relationship between components of the interpersonal-psychological theory of suicidal behavior and lifetime number of suicide attempts. Journal of Affective Disorders, 129(1-3), 261-269. 10.1016/j.jad.2010.08.006 [PubMed: 20825997]

Baker TB, Piper ME, McCarthy DE, Majeskie MR, \& Fiore MC (2004). Addiction motivation reformulated: An affective processing model of negative reinforcement. Psychological Review, 111(1), 33-51. 10.1037/0033-295X.111.133 [PubMed: 14756584]

Bandura A (1994). Social cognitive theory and exercise of control over HIV infection In DiClemente RJ \& Peterson JL (Eds.), Preventing AIDS: Theories and Methods of Behavioral Intervention (pp. 25-59). New York: Plenum Press.

Boodram B, Golub ET, \& Ouellet LJ (2010). Socio-behavioral and geographic correlates of prevalent hepatitis $\mathrm{C}$ virus infection among young injection drug users in metropolitan Baltimore and Chicago. Drug and Alcohol Dependence, 111(1-2), 136-145. http://dx.doi.org/ 10.10167j.drugalcdep.2010.04.003 [PubMed: 20472373]

Boodram B, Hotton AL, Shekhtman L, Gutfraind A, \& Dahari H (2018). High-risk geographic mobility patterns among young urban and suburban persons who inject drugs and their injection network members. Journal of Urban Health, 95(1), 71-82. 10.1007/s11524-017-0185-7 [PubMed: 28875410]

Boodram B, Kaufmann M, Aronsohn A, Hamlish T, Peregrine Antalis E, Kim K, ... Johnson D. (2020). Case Management and Capacity Building to Enhance Hepatitis C Treatment Uptake at Community Health Centers in a Large Urban Setting. Family and Community Health, 43(2), 150160. 10.1097/fch.0000000000000253 [PubMed: 32079971]

Boodram B, Mackesy-Amiti ME, \& Latkin C (2015). The role of social networks and geography on risky injection behaviors of young persons who inject drugs. Drug and Alcohol Dependence, 154, 229-235. 10.1016/j.drugalcdep.2015.06.042 [PubMed: 26169447]

Centers for Disease Control and Prevention. (2012). HIV infection and HIV-associated behaviors among injecting drug users - 20 cities, United States, 2009. Morbidity and Mortality Weekly Report, 61(8), 133-138. [PubMed: 22377843]

Centers for Disease Control and Prevention. (2017). New Hepatitis C Infections Nearly Tripled over Five Years [Press release]. Retrieved from https://www.cdc.gov/nchhstp/newsroom/2017/HepatitisSurveillance-Press-Release.html

Centers for Disease Control and Prevention. (2018). Surveillance for Viral Hepatitis -- United States, 2016. Retrieved from https://www.cdc.gov/hepatitis/statistics/2016surveillance/index.htm

Chatterjee S, Tempalski B, Pouget ER, Cooper HL, Cleland CM, \& Friedman SR (2011). Changes in the prevalence of injection drug use among adolescents and young adults in large U.S. metropolitan areas. AIDS and Behavior, 15(7), 1570-1578. 10.1007/s10461-011-9992-0 [PubMed: 21739288]

Cheetham A, Allen NB, Yucel M, \& Lubman DI (2010). The role of affective dysregulation in drug addiction. Clinical Psychology Review, 30(6), 621-634. 10.1016/j.cpr.2010.04.005 [PubMed: 20546986]

Chen KW, Banducci AN, Guller L, Macatee RJ, Lavelle A, Daughters SB, \& Lejuez CW (2011). An examination of psychiatric comorbidities as a function of gender and substance type within an inpatient substance use treatment program. Drug and Alcohol Dependence, 118(2-3), 92-99. 10.1016/j.drugalcdep.2011.03.003 [PubMed: 21514751]

Compton WM, Thomas YF, Stinson FS, \& Grant BF (2007). Prevalence, correlates, disability, and comorbidity of DSM-IV drug abuse and dependence in the United States: Results from the National Epidemiologic Survey on Alcohol and Related Conditions. Archives of General Psychiatry, 64(5), 566-576. 10.1001/archpsyc.64.5.566 [PubMed: 17485608]

Crowell SE, Beauchaine TP, \& Linehan MM (2009). A biosocial developmental model of borderline personality: Elaborating and extending Linehan's theory. Psychological Bulletin, 135(3), 495-510. 10.1037/a0015616 [PubMed: 19379027] 
Curran PJ, \& Bauer DJ (2011). The disaggregation of within-person and between-person effects in longitudinal models of change. Annual Review of Psychology, 62, 583-619. 10.1146/ annurev.psych.093008.100356

Cyders MA, Littlefield AK, Coffey S, \& Karyadi KA (2014). Examination of a short version of the UPPS-P impulsive behavior scale. Addictive Behaviors, 39(9), 1372-1376. 10.1016/ j.addbeh.2014.02.013 [PubMed: 24636739]

Cyders MA, \& Smith GT (2007). Mood-based rash action and its components: Positive and negative urgency. Personality and Individual Differences, 43(4), 839-850. 10.1016/j.paid.2007.02.008

Cyders MA, \& Smith GT (2008). Emotion-based dispositions to rash action: Positive and negative urgency. Psychological Bulletin, 134(6), 807-828. 10.1037/a0013341 [PubMed: 18954158]

Cyders MA, Smith GT, Spillane NS, Fischer S, Annus AM, \& Peterson C (2007). Integration of impulsivity and positive mood to predict risky behavior: Development and validation of a measure of positive urgency. Psychological Assessment, 19(1), 107-118. 10.1037/1040-3590.19.1.107 [PubMed: 17371126]

Darke S, Ross J, Williamson A, Mills KL, Havard A, \&Teesson. (2007). Borderline personality disorder and persistently elevated levels of risk in 36-month outcomes for the treatment of heroin dependence. Addiction, 102(7), 1140-1146. 10.1111/j.1360-0443.2007.01876.x [PubMed: 17567402]

Darke S, Ross J, Williamson A, \&Teesson M. (2005). The impact of borderline personality disorder on 12-month outcomes for the treatment of heroin dependence. Addiction, 100(8), 1121-1130. 10.1111/j.1360-0443.2005.01123.x [PubMed: 16042642]

Darke S, Williamson A, Ross J, Teesson M, \& Lynskey M (2004). Borderline personality disorder, antisocial personality disorder and risk-taking among heroin users: Findings from the Australian Treatment Outcome Study (ATOS). Drug and Alcohol Dependence, 74(1), 77-83. 10.1016/ j.drugalcdep.2003.12.002 [PubMed: 15072810]

Deckman T, \& DeWall CN (2011). Negative urgency and risky sexual behaviors: A clarification of the relationship between impulsivity and risky sexual behavior. Personality and Individual Differences, 51(5), 674-678.

Dir AL, Karyadi K, \& Cyders MA (2013). The uniqueness of negative urgency as a common risk factor for self-harm behaviors, alcohol consumption, and eating problems. Addictive Behaviors, 38(5), 2158-2162. 10.1016/j.addbeh.2013.01.025 [PubMed: 23454879]

Disney E, Kidorf M, Kolodner K, King V, Peirce J, Beilenson P, \& Brooner RK (2006). Psychiatric comorbidity is associated with drug use and HIV risk in syringe exchange participants. Journal of Nervous and Mental Disease, 194(8), 577-583. 10.1097/01.nmd.0000230396.17230.28 [PubMed: 16909065]

Ebner-Priemer UW, Kuo J, Welch SS, Thielgen T, Witte S, Bohus M, \& Linehan MM (2006). A valence-dependent group-specific recall bias of retrospective self-reports - A study of borderline personality disorder in everyday life. Journal of Nervous and Mental Disease, 194(10), 774-779. 10.1097/01.nmd.0000239900.46595.72 [PubMed: 17041290]

Ebner-Priemer UW, \& Trull TJ (2009a). Ambulatory assessment: An innovative and promising approach for clinical psychology. European Psychologist, 14(2), 109-119. 10.1027/1016-9040.14.2.109

Ebner-Priemer UW, \& Trull TJ (2009b). Ecological momentary assessment of mood disorders and mood dysregulation. Psychological Assessment, 21(4), 463-475. 10.1037/a0017075 [PubMed: 19947781]

Fishbein M, \& Middlestadt S (1989). Using the theory of reasoned action as a framework for understanding and changing AIDS-related behaviors In Mays V, Albee G, \& Schneider S (Eds.), Primary Prevention of AIDS: Psychological Approaches (pp. 93-110). Newbury Park: Sage.

Fisher WA, Fisher JD, \& Harman J (2003). The information-motivation-behavioral skills model: A general social psychological approach to understanding and promoting health behavior In Suls J \& Wallston KA (Eds.), Social Psychological Foundations of Health and Illness (pp. 82-106). Malden, MA: Blackwell Publishing. 
Fox HC, Axelrod SR, Paliwal P, Sleeper J, \& Sinha R (2007). Difficulties in emotion regulation and impulse control during cocaine abstinence. Drug and Alcohol Dependence, 89(2-3), 298-301. 10.1016/j.drugalcdep.2006.12.026 [PubMed: 17276626]

Fox HC, Hong KA, \& Sinha R (2008). Difficulties in emotion regulation and impulse control in recently abstinent alcoholics compared with social drinkers. Addictive Behaviors, 33(2), 388-394. 10.1016/j.addbeh.2007.10.002 [PubMed: 18023295]

Gardner K, \& Qualter P (2009). Reliability and validity of three screening measures of borderline personality disorder in a nonclinical population. Personality and Individual Differences, 46(5), 636-641.

German D, Davey M, \& Latkin C (2007). Residential transience and HIV risk behaviors among injection drug users. AIDS and Behavior, 11(2), 21-30. 10.1007/s10461-007-9238-3 [PubMed: 17486437]

Gilchrist G, Blazquez A, \& Torrens M (2011). Psychiatric, behavioural and social risk factors for HIV infection among female drug users. AIDS and Behavior, 15(8), 1834-1843. 10.1007/ s10461-011-9991-1 [PubMed: 21748277]

Glenn CR, \& Klonsky ED (2010). A multimethod analysis of impulsivity in nonsuicidal self-injury. Personality Disorders: Theory, Research, and Treatment, 1(1), 67-75. 10.1037/a0017427

Gratz KL, \& Roemer L (2004). Multidimensional assessment of emotion regulation and dysregulation: Development, factor structure, and initial validation of the Difficulties in Emotion Regulation Scale. Journal of Psychopathology and Behavioral Assessment, 26(1), 41-54. 10.1023/ b:joba.0000007455.08539.94

Grebely J, Larney S, Peacock A, Colledge S, Leung J, Hickman M, ... Degenhardt L (2018). Global, regional, and country-level estimates of hepatitis $\mathrm{C}$ infection among people who have recently injected drugs. Addiction, 10.1111/add.14393

Grella CE, Karno MP, Warda US, Niv N, \& Moore AA (2009). Gender and comorbidity among individuals with opioid use disorders in the NESARC study. Addictive Behaviors, 34(8-7), 498504. 10.1016/j.addbeh.2009.01.002 [PubMed: 19232832]

Hagan H, Thiede H, Weiss NS, Hopkins SG, Duchin JS, \& Alexander ER (2001). Sharing of drug preparation equipment as a risk factor for hepatitis C. American Journal of Public Health, 91(1), 42-46. 10.2105/AJPH.91.1.42 [PubMed: 11189822]

Hotton AL, \& Boodram B (2017). Gender, transience, network partnerships and risky sexual practices among young persons who inject drugs. AIDS and Behavior, 21(4), 982-993. 10.1007/ s10461-016-1555-y [PubMed: 27637498]

ilumivu Inc. (2016) http://mema.ilumivu.com/

Kassel JD, Greenstein JE, Evatt DP, Roesch LL, Veilleux JC, Wardle MC, \& Yates MC (2007). Negative Affect and Addiction In al'Absi M (Ed.), Stress and Addiction (pp. 171-189). Burlington: Academic Press.

King VL, Kidorf MS, Stoller KB, \& Brooner RK (2000). Influence of psychiatric comorbidity on HIV risk behaviors: Changes during drug abuse treatment. Journal of Addictive Diseases, 19(4), 65-83. [PubMed: 11110066]

Klonsky ED, \& May A (2010). Rethinking impulsivity in suicide. Suicide and Life-Threatening Behavior, 40(6), 612-619. 10.1521/suli.2010.40.6.612 [PubMed: 21198330]

Koob G, \& Kreek MJ (2007). Stress, dysregulation of drug reward pathways, and the transition to drug dependence. American Journal of Psychiatry, 164(8), 1149-1159. 10.1176/ appi.ajp.2007.05030503 [PubMed: 17671276]

Koob GF (2009). Dynamics of neuronal circuits in addiction: Reward, antireward, and emotional memory. Pharmacopsychiatry, 42, S32-S41. 10.1055/s-0029-1216356 [PubMed: 19434554]

Lieb K, Zanarini MC, Schmahl C, Linehan MM, \& Bohus M (2004). Borderline personality disorder. Lancet, 364(9432), 453-461. [PubMed: 15288745]

Linehan MM (1993). Cognitive-Behavioral Treatment of Borderline Personality Disorder. New York: Guilford.

Lynam DR, Miller JD, Miller DJ, Bornovalova MA, \& Lejuez CW (2011). Testing the relations between impulsivity-related traits, suicidality, and nonsuicidal self-injury: A test of the incremental 
validity of the UPPS model. Personality Disorders: Theory, Research, and Treatment, 2(2), 151160. $10.1037 / \mathrm{a} 0019978$

Mackesy-Amiti ME, \& Boodram B (2018). Feasibility of ecological momentary assessment to study mood and risk behavior among young people who inject drugs. Drug and Alcohol Dependence, 187, 227-235. 10.1016/j.drugalcdep.2018.03.016 [PubMed: 29684890]

Mackesy-Amiti ME, Boodram B, \& Donenberg G (2019). Negative affect, affect-related impulsivity, and receptive syringe sharing among people who inject drugs. Preprint. PsyArXiv. DOI: 10.31234/ osf.io/4ewn6

Mackesy-Amiti ME, \& Donenberg G (2020). Negative affect and emotion dysregulation among people who inject drugs: An ecological momentary assessment study. Psychology of Addictive Behaviors, In Press 10.1037/adb0000577

Mackesy-Amiti ME, Donenberg GR, \& Ouellet LJ (2012). Prevalence of psychiatric disorders among young injection drug users. Drug and Alcohol Dependence, 124(1-2), 70-78. 10.1016/ j.drugalcdep.2011.12.012 [PubMed: 22226707]

Mackesy-Amiti ME, Donenberg GR, \& Ouellet LJ (2014). Psychiatric correlates of injection risk behavior among young people who inject drugs. Psychology of Addictive Behaviors, 28(4), 10891095. 10.1037/a0036390 [PubMed: 25134053]

Majer JM, Komer AC, \& Jason LA (2015). Psychiatric severity and HIV-risk sexual behaviors among persons with substance use disorders. Journal of Dual Diagnosis, 11(1), 3-11. 10.1080/15504263.2014.990802 [PubMed: 25455334]

Mills KL, Teesson M, Darke S, Ross J, \& Lynskey M (2004). Young people with heroin dependence: Findings from the Australian Treatment Outcome Study (ATOS). Journal of Substance Abuse Treatment, 27(1), 67-73. 10.1016/j.jsat.2004.05.001 [PubMed: 15223096]

Mirhashem R, Allen HC, Adams ZW, van Stolk-Cooke K, Legrand A, \& Price M (2017). The intervening role of urgency on the association between childhood maltreatment, PTSD, and substance-related problems. Addictive Behaviors, 69, 98-103. [PubMed: 28219827]

Muthén LK, \& Muthén BO (2017). MPlus (Version 8): Muthén \& Muthén Retrieved from www.statmodel.com

Myrick H, \& Brady K (2003). Current review of the comorbidity of affective, anxiety, and substance use disorders. Current Opinion in Psychiatry, 16(3), 261-270. 10.1097/01.yco.0000069080.26384.d8

National Academies of Sciences Engineering and Medicine. (2016). Eliminating the Public Health Problem of Hepatitis B and C in the United States: Phase One Report. Washington (DC): National Academies Press (US), 10.17226/23407

National Institute on Drug Abuse. (1993). Risk Behavior Assessment (3rd ed.). Rockville, MD: NIDA Community Research Branch 10.3886/ICPSR03023

Needle R, Fisher DG, Weatherby N, Chitwood D, Brown B, Cesari H, ... Braunstein M (1995). Reliability of self-reported HIV risk behaviors of drug users. Psychology of Addictive Behaviors, 9(4), 242-250. 10.1037/0893-164X.9.4.242

Patel AB, Sharp C, \& Fonagy P (2011). Criterion validity of the MSI-BPD in a community sample of women. Journal of Psychopathology and Behavioral Assessment, 33(3), 403-408. 10.1007/ s10862-011-9238-5

Peters JR, Upton BT, \& Baer RA (2012). Relationships between facets of impulsivity and borderline personality features. Journal of Personality Disorders, 27(4), 547-552. 10.1521/ pedi_2012_26_044 [PubMed: 22984862]

Peterson CM, Davis-Becker K, \& Fischer S (2014). Interactive role of depression, distress tolerance and negative urgency on non-suicidal self-injury. Personality and Mental Health, 8(2), 151-160. 10.1002/pmh.1256 [PubMed: 24469979]

Pilowsky DJ, Wu L-T, Burchett B, Blazer DG, \& Ling W (2011). Depressive symptoms, substance use, and HIV-related high-risk behaviors among opioid-dependent individuals: Results from the Clinical Trials Network. Substance Use and Misuse, 46(14), 1716-1725. 10.3109/10826084.2011.611960 [PubMed: 21973307]

Platt L, Minozzi S, Reed J, Vickerman P, Hagan H, French C, ... Hickman M (2018). Needle and syringe programmes and opioid substitution therapy for preventing HCV transmission among 
people who inject drugs: Findings from a Cochrane Review and meta-analysis. Addiction, 113(3), 545-563. 10.1111/add.14012 [PubMed: 28891267]

Pouget ER, Hagan H, \& Des Jarlais DC (2012). Meta-analysis of hepatitis C seroconversion in relation to shared syringes and drug preparation equipment. Addiction, 107(6), 1057-1065. 10.1111/ j.1360-0443.2011.03765.x [PubMed: 22168373]

Press WH, Teukolsky SA, Vetterling WT, \& Flannery BP (2007). Numerical Recipes: The Art of Scientific Computing (Third ed.). Cambridge, UK: Cambridge University Press.

Riley EN, Combs JL, Jordan CE, \& Smith GT (2015). Negative urgency and lack of perseverance: Identification of differential pathways of onset and maintenance risk in the longitudinal prediction of nonsuicidal self-injury. Behavior Therapy, 46(4), 439-448. [PubMed: 26163709]

Rounsaville BJ, Kranzler HR, Ball S, Tennen H, Poling J, \&Triffleman E (1998). Personality disorders in substance abusers: Relation to substance use. Journal of Nervous and Mental Disease, 186(2), 87-95. 10.1097/00005053-199802000-00004 [PubMed: 9484308]

Roy É, Levesque A, Bruneau J, Jutras-Aswad D, \& Bertrand K (2014). Psychological distress increases needle sharing among cocaine users: Results from the COSMO study. Journal of Addiction Research and Therapy, S10, 003 10.4172/2155-6105.S10-003

Roy É, Robert M, Vaillancourt É, Boivin J-F, Vandermeerschen J, \& Martin I (2011). Residential trajectory and HIV high-risk behaviors among Montreal street youth-a reciprocal relationship. Journal of Urban Health, 88(4), 767-778. 10.1007/s11524-011-9574-5 [PubMed: 21494896]

Shiffman S, Stone AA, \& Hufford MR (2008). Ecological momentary assessment. Annual Review of Clinical Psychology, 4, 1-32. 10.1146/annurev.clinpsy.3.022806.091415

StataCorp. (2017). Stata Statistical Software: Release 15 (Version 15). College Station, TX Retrieved from http://www.stata.com

Stein MD, Solomon DA, Herman DS, Anderson BJ, \& Miller I (2003). Depression severity and drug injection HIV risk behaviors. American Journal of Psychiatry, 160(9), 1659-1662. 10.1176/ appi.ajp.160.9.1659 [PubMed: 12944342]

Thorpe LE, Ouellet LJ, Hershow R, Bailey SL, Williams IT, Williamson J, ... Garfein RS (2002). Risk of hepatitis $\mathrm{C}$ virus infection among young adult injection drug users who share injection equipment. American Journal of Epidemiology, 155(7), 645-653. 10.1093/aje/155.7.645 [PubMed: 11914192]

Torrens M, Gilchrist G, \& Domingo-Salvany A (2011). Psychiatric comorbidity in illicit drug users: Substance-induced versus independent disorders. Drug and Alcohol Dependence, 113(2-3), 147156. 10.1016/j.drugalcdep.2010.07.013 [PubMed: 20801586]

Tragesser SL, \& Robinson RJ (2009). The role of affective instability and UPPS impulsivity in borderline personality disorder features. Journal of Personality Disorders, 23(4), 370-383. 10.1521/pedi.2009.23.4.370 [PubMed: 19663657]

Trull TJ, Sher KJ, Minks-Brown C, Durbin J, \& Burr R (2000). Borderline personality disorder and substance use disorders: A review and integration. Clinical Psychology Review, 20(2), 235-253. 10.1016/S0272-7358(99)00028-8 [PubMed: 10721499]

Verheul R (2001). Co-morbidity of personality disorders in individuals with substance use disorders. European Psychiatry, 16(5), 274-282. 10.1016/S0924-9338(01)00578-8 [PubMed: 11514129]

Wardell JD, Strang NM, \& Hendershot CS (2016). Negative urgency mediates the relationship between childhood maltreatment and problems with alcohol and cannabis in late adolescence. Addictive Behaviors, 56, 1-7. 10.1016/j.addbeh.2016.01.003 [PubMed: 26774820]

Watson D, \& Clark LA (1999). The PANAS-X: Manual for the Positive and Negative Affect ScheduleExpanded Form. University of Iowa Retrieved from http://www2.psychology.uiowa.edu/faculty/ Watson/PANAS-X.pdf

Watson D, Clark LA, \& Tellegen A (1988). Development and validation of brief measures of positive and negative affect: The PANAS scales. Journal of Personality and Social Psychology, 54(6), 1063-1070. 10.1037/0022-3514.54.6.1063 [PubMed: 3397865]

Weatherby NL, Needle R, Cesari H, Booth R, McCoy CB, Watters JK, ... Chitwood DD (1994). Validity of self-reported drug use among injection drug users and crack cocaine users recruited through street outreach. Evaluation and Program Planning, 17(4), 347-355. 10.1016/0149-7189(94)90035-3 
Weiss NH, Sullivan TP, \& Tull MT (2015). Explicating the role of emotion dysregulation in risky behaviors: A review and synthesis of the literature with directions for future research and clinical practice. Current Opinion in Psychology, 3, 22-29. 10.1016/j.copsyc.2015.01.013 [PubMed: 25705711]

Whiteside SP, \& Lynam DR (2001). The Five Factor Model and impulsivity: Using a structural model of personality to understand impulsivity. Personality and Individual Differences, 30(4), 669-689. 10.1016/S0191-8869(00)00064-7

Whiteside SP, Lynam DR, Miller JD, \& Reynolds SK (2005). Validation of the UPPS impulsive behaviour scale: A four-factor model of impulsivity. European Journal of Personality, 19(7), 559574. 10.1002/per.556

Zanarini MC, Vujanovic AA, Parachini EA, Boulanger JL, Frankenburg FR, \& Hennen J (2003). A screening measure for BPD: The McLean Screening Instrument for Borderline Personality Disorder (MSI-BPD). Journal of Personality Disorders, 17(6), 568-573. 10.1521/ pedi.17.6.568.25355 [PubMed: 14744082]

Zibbell JE, Asher AK, Patel RC, Kupronis B, Iqbal K, Ward JW, \& Holtzman D (2018). Increases in acute hepatitis $\mathrm{C}$ virus infection related to a growing opioid epidemic and associated injection drug use, United States, 2004 to 2014. American Journal of Public Health, 108(2), 175-181. 10.2105/ ajph.2017.304132 [PubMed: 29267061]

Zibbell JE, Iqbal K, Patel RC, Suryaprasad A, Sanders KJ, Moore-Moravian L, ... Holtzman D. (2015). Increases in hepatitis $C$ virus infection related to injection drug use among persons aged $</=30$ years - Kentucky, Tennessee, Virginia, and West Virginia, 2006-2012. MMWR. Morbidity and Mortality Weekly Report, 64(17), 453-458. [PubMed: 25950251] 

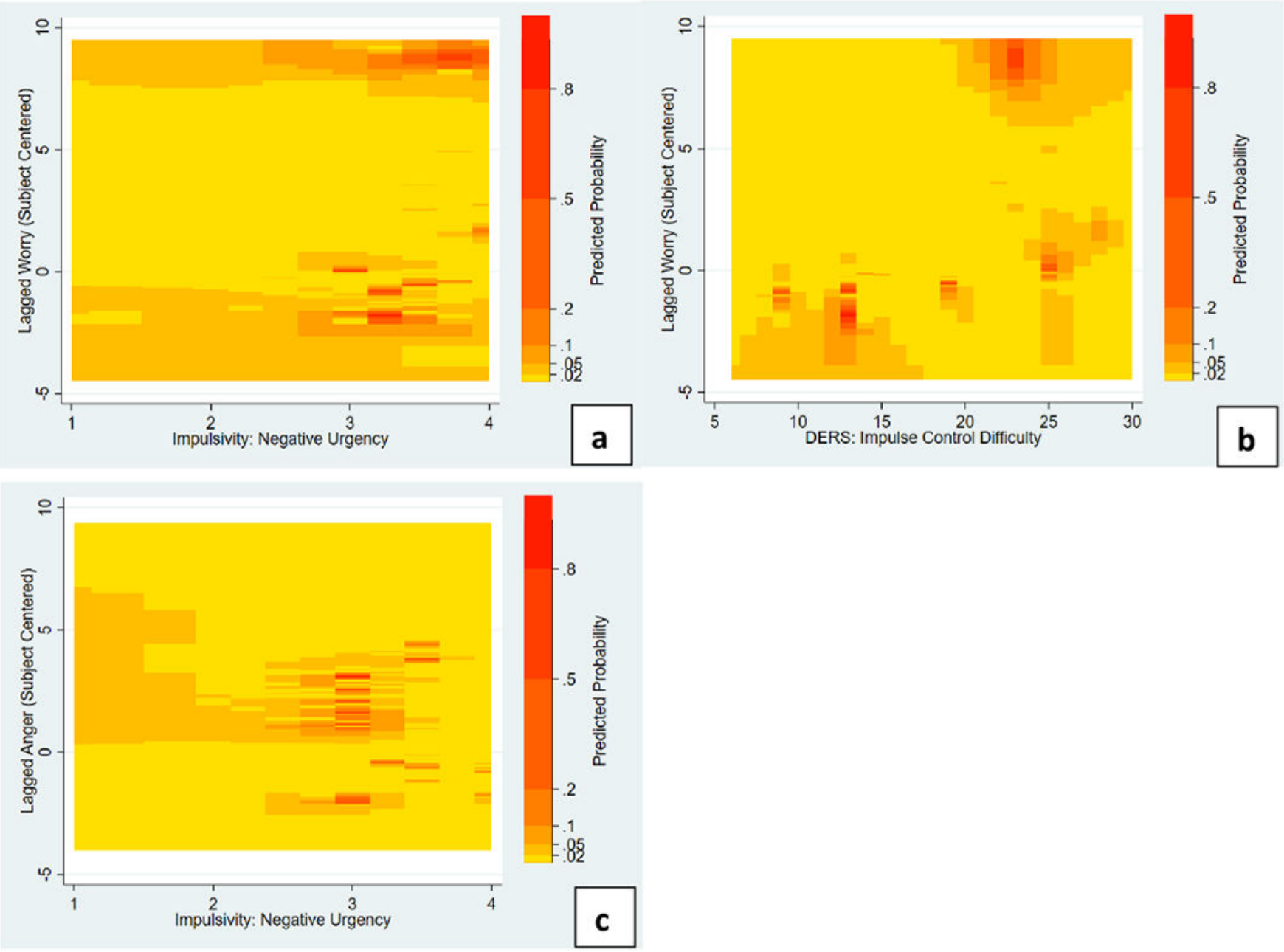

Figure 1. Predicted Probability of Receptive Syringe Sharing (RSS)

Note: The predicted probability of receptive syringe sharing (RSS) based on the final model plotted by (a) negative urgency and preceding worry, (b) DERS impulsivity and preceding worry, and (c) negative urgency and preceding anger. 


\section{Table 1.}

Characteristics of the sample $(\mathrm{N}=163)$

\begin{tabular}{|c|c|c|}
\hline Variable & $n$ & $\%$ \\
\hline \multicolumn{3}{|l|}{ Sex } \\
\hline Male & 111 & 68.1 \\
\hline Female & 52 & 31.9 \\
\hline Age, Mean $(S D)$ & \multicolumn{2}{|c|}{$29.6(3.9)$} \\
\hline \multicolumn{3}{|l|}{ Race/Ethnicity } \\
\hline White, non-Hispanic & 101 & 62.0 \\
\hline Black, non-Hispanic & 12 & 7.4 \\
\hline Hispanic & 37 & 22.7 \\
\hline Other, non-Hispanic ${ }^{a}$ & 11 & 6.7 \\
\hline \multicolumn{3}{|l|}{ Highest level of education } \\
\hline Less than high school & 33 & 20.2 \\
\hline High school graduate (12th grade) or GED & 63 & 38.7 \\
\hline Some college or technical training & 50 & 30.7 \\
\hline College graduate or higher & 15 & 9.2 \\
\hline \multicolumn{3}{|l|}{ Residence (place slept most past 6 months) } \\
\hline Chicago & 97 & 59.5 \\
\hline Outside of Chicago & 66 & 40.5 \\
\hline \multicolumn{3}{|l|}{ Homelessness past 6 months } \\
\hline Not homeless & 65 & 39.9 \\
\hline Thought of as homeless & 34 & 20.9 \\
\hline Slept in non-dwelling $>7$ nights & 64 & 39.3 \\
\hline \multicolumn{3}{|l|}{ Frequency of injection past 6 months } \\
\hline Less than daily & 43 & 26.4 \\
\hline Daily, 1 to 4 times per day & 71 & 43.6 \\
\hline Daily, 5 or more times per day & 46 & 28.2 \\
\hline \multicolumn{3}{|l|}{ Receptive syringe sharing past 6 months } \\
\hline Never & 91 & 55.8 \\
\hline Rarely & 35 & 21.5 \\
\hline Sometimes & 36 & 22.1 \\
\hline \multicolumn{3}{|l|}{ BPD screening score } \\
\hline Low $(<7)$ & 49 & 30.1 \\
\hline $\operatorname{High}(\geq 7)$ & 114 & 69.9 \\
\hline Negative urgency impulsivity: Mean $(S D)$ & \multicolumn{2}{|c|}{$3.18(0.58)$} \\
\hline DERS impulsivity: Mean (SD) & \multicolumn{2}{|c|}{$16.19(5.54)$} \\
\hline PID negative affect: Mean $(S D)$ & \multicolumn{2}{|c|}{$1.67(0.73)$} \\
\hline
\end{tabular}

Includes Asian, Pacific Islander, Native American, Black or African-American, mixed race, and unidentified race.

DERS: Difficulties with Emotion Regulation Scale

PID: Personality Inventory for DSM-5 
Note: some percentages add to less than $100 \%$ due to missing data. 
Table 2.

Multilevel mixed effects logistic regression on receptive syringe sharing during injection event: Effects of negative affect preceding the injection event and interactions with NU impulsivity, N=152 Ss, 1,559 obs

\begin{tabular}{|c|c|c|c|c|c|}
\hline \multirow{2}{*}{$\frac{\text { Effect }}{\text { Total NA }^{a}}$} & \multirow{2}{*}{$\frac{\text { OR }}{0.94}$} & \multirow{2}{*}{$\frac{\mathbf{S E}}{0.25}$} & \multicolumn{2}{|c|}{ 95\% Conf. Int. } & \multirow{2}{*}{$\frac{\mathbf{p}}{0.813}$} \\
\hline & & & 0.56 & 1.57 & \\
\hline NU (Std.) & 1.94 & 0.75 & 0.91 & 4.16 & 0.088 \\
\hline Total NA x NU & 0.95 & 0.38 & 0.43 & 2.10 & 0.901 \\
\hline Mean Total NA ${ }^{b}$ & 1.21 & 1.09 & 0.21 & 7.08 & 0.829 \\
\hline Dejection $^{a}$ & 0.96 & 0.06 & 0.85 & 1.08 & 0.459 \\
\hline NU (Std.) & 1.82 & 0.68 & 0.87 & 3.77 & 0.110 \\
\hline Dejection x NU & 1.09 & 0.14 & 0.84 & 1.42 & 0.512 \\
\hline Mean dejection ${ }^{b}$ & 4.10 & 3.17 & 0.90 & 18.64 & 0.068 \\
\hline Shame $^{a}$ & 1.01 & 0.02 & 0.96 & 1.05 & 0.782 \\
\hline NU (Std.) & 2.04 & 0.86 & 0.89 & 4.67 & 0.091 \\
\hline Shame x NU & 1.01 & 0.06 & 0.89 & 1.14 & 0.909 \\
\hline Mean shame ${ }^{b}$ & 0.85 & 0.69 & 0.17 & 4.20 & 0.838 \\
\hline Anger $^{a}$ & 0.97 & 0.06 & 0.85 & 1.10 & 0.619 \\
\hline NU (Std.) & 2.04 & 0.80 & 0.95 & 4.38 & 0.067 \\
\hline Anger x NU & 0.77 & 0.08 & 0.62 & 0.95 & 0.016 \\
\hline Mean anger ${ }^{b}$ & 1.12 & 0.91 & 0.23 & 5.47 & 0.888 \\
\hline Irritability $^{a}$ & 0.89 & 0.16 & 0.62 & 1.27 & 0.529 \\
\hline NU (Std.) & 2.10 & 0.73 & 1.06 & 4.16 & 0.033 \\
\hline Irritability x NU & 1.00 & 0.19 & 0.69 & 1.45 & 0.994 \\
\hline Mean irritability ${ }^{b}$ & 0.65 & 0.26 & 0.30 & 1.43 & 0.286 \\
\hline Worry $^{a}$ & 0.57 & 0.21 & 0.28 & 1.16 & 0.120 \\
\hline NU (Std.) & 2.33 & 0.98 & 1.02 & 5.32 & 0.044 \\
\hline Worry x NU & 2.45 & 0.88 & 1.21 & 4.95 & 0.013 \\
\hline Mean worry $b$ & 1.48 & 0.78 & 0.52 & 4.18 & 0.464 \\
\hline${ }^{a}$ Within-person effe & 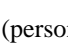 & 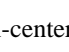 & 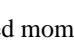 & ry aft & \\
\hline etween-person e & (c) & 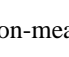 & $\mathrm{ffec}$ & all c & ervations) \\
\hline NA: Negative affect; & NU: N & ative & ency & d: Stand & rdized \\
\hline
\end{tabular}

Psychol Addict Behav. Author manuscript; available in PMC 2021 November 01. 
Table 3.

Mixed effects logistic regression on receptive syringe sharing during injection event: Effects of negative affect preceding the injection event and interactions with DERS impulsivity, N=152 Ss, 1,559 obs

\begin{tabular}{|c|c|c|c|c|c|}
\hline \multirow{2}{*}{$\frac{\text { Effect }}{\text { Total NA }^{a}}$} & \multirow{2}{*}{$\frac{\text { OR }}{0.46}$} & \multirow{2}{*}{$\frac{\mathbf{S E}}{0.21}$} & \multicolumn{2}{|c|}{ 95\% Conf. Int. } & \multirow{2}{*}{$\frac{\mathbf{p}}{0.095}$} \\
\hline & & & 0.18 & 1.15 & \\
\hline DERS Impulsivity (Std.) & 1.43 & 0.77 & 0.50 & 4.08 & 0.499 \\
\hline Total NA x DERS Impulsivity & 1.78 & 0.45 & 1.08 & 2.91 & 0.022 \\
\hline Mean Total NA ${ }^{b}$ & 1.15 & 0.90 & 0.25 & 5.35 & 0.856 \\
\hline Dejection $^{a}$ & 0.96 & 0.13 & 0.73 & 1.25 & 0.752 \\
\hline DERS Impulsivity (Std.) & 1.13 & 0.57 & 0.42 & 3.06 & 0.803 \\
\hline Dejection x DERS Impulsivity & 1.01 & 0.10 & 0.84 & 1.23 & 0.893 \\
\hline Mean dejection $b$ & 4.20 & 2.96 & 1.05 & 16.73 & 0.042 \\
\hline Shame $^{a}$ & 1.06 & 0.08 & 0.92 & 1.23 & 0.402 \\
\hline DERS Impulsivity (Std.) & 1.41 & 0.69 & 0.54 & 3.68 & 0.483 \\
\hline Shame x DERS Impulsivity & 0.96 & 0.04 & 0.89 & 1.05 & 0.374 \\
\hline Mean shame $b$ & 0.83 & 0.58 & 0.21 & 3.25 & 0.790 \\
\hline Anger $^{a}$ & 0.86 & 0.06 & 0.74 & 0.99 & 0.042 \\
\hline DERS Impulsivity (Std.) & 1.37 & 0.65 & 0.54 & 3.48 & 0.504 \\
\hline Anger x DERS Impulsivity & 1.10 & 0.10 & 0.91 & 1.32 & 0.326 \\
\hline Mean anger ${ }^{b}$ & 1.01 & 0.66 & 0.28 & 3.61 & 0.984 \\
\hline Irritability $^{a}$ & 0.89 & 0.18 & 0.60 & 1.34 & 0.585 \\
\hline DERS Impulsivity (Std.) & 1.48 & 0.85 & 0.48 & 4.57 & 0.500 \\
\hline Irritability x DERS Impulsivity & 0.99 & 0.19 & 0.68 & 1.45 & 0.952 \\
\hline Mean irritability $b$ & 0.67 & 0.30 & 0.27 & 1.61 & 0.367 \\
\hline Worry $^{a}$ & 0.53 & 0.22 & 0.24 & 1.19 & 0.123 \\
\hline DERS Impulsivity (Std.) & 1.35 & 0.73 & 0.47 & 3.92 & 0.579 \\
\hline Worry x DERS Impulsivity & 2.46 & 0.77 & 1.33 & 4.54 & 0.004 \\
\hline Mean worry ${ }^{b}$ & 1.29 & 0.60 & 0.52 & 3.21 & 0.579 \\
\hline
\end{tabular}

${ }^{a}$ Within-person effect (person-centered momentary affect)

$b_{\text {Between-person effect (person-mean affect over all observations) }}$

NA: Negative affect; NU: Negative urgency; Std: Standardized

Models are adjusted for day, time of day, and homelessness 
Table 4.

Mixed effects logistic regression on receptive syringe sharing during injection event: Effects of worry and anger preceding the injection event and interactions with NU and DERS impulsivity, N=152 Ss, 1,559 obs

\begin{tabular}{lccccc} 
Effect & OR & SE & 95\% Conf. Int. & p \\
\hline Worry $^{a}$ & 0.38 & 0.16 & 0.17 & 0.88 & 0.023 \\
DERS Impulsivity (Std.) & 1.07 & 0.70 & 0.30 & 3.85 & 0.916 \\
Worry x DERS Impulsivity & 2.24 & 0.68 & 1.24 & 4.05 & 0.008 \\
NU (Std.) & 2.11 & 1.18 & 0.71 & 6.34 & 0.181 \\
Worry x NU & 1.73 & 0.51 & 0.97 & 3.07 & 0.061 \\
Anger & \\
Anger x NU & 0.96 & 0.06 & 0.85 & 1.09 & 0.556 \\
Mean worry $^{b}$ & 0.74 & 0.08 & 0.59 & 0.93 & 0.009 \\
Mean anger $^{b}$ & 1.29 & 0.91 & 0.32 & 5.16 & 0.720 \\
\hline
\end{tabular}

${ }^{a}$ Within-person effect (person-centered momentary affect)

$b_{\text {Between-person effect (person-mean affect over all observations) }}$

NA: Negative affect; NU: Negative urgency; DERS: Difficulties with Emotion Regulation Scale; Std: Standardized

Model is adjusted for day, time of day, and homelessness 